\title{
Применимость теории войны Клаузевица к разрешению современных конфликтов
}

\section{Ясмин Чаич}

Учебный чентр для операций по поддержанию мира, штаб - лагерь Бутмир, 71000 Сараево, Босния и Герцеговина, http://www.psotc.org

Резюме: В этой статье доказывается, что труды Клаузевица о войне, написанные почти 200 лет назад, все еще актуальны для разрешения современных конфликтов как минимум в трех аспектах: его идея, что война является «продолжением политики другими средствами»; второе, его анализ природы войны и его теория троицы; и последнее, его понимание характера стратегии. В результате анализа, приведенного в этой статье, было установлено, что если есть хорошая политика, из которой можно вывести стратегию, и если мы в состоянии применить ее эффективно, с помощью людей и международного сообщества, мы можем создать серьезные предпосылки, чтобы выиграть войну.

Кроме того, точка зрения Клаузевица на вопросы, связанные с войной, стратегией и разрешением конфликтов, имеет важное значение для понимания главных проблем и принятия решений даже тогда, когда история и реальность ограничивают его абстракции современным опытом. Его теории и концепции сегодня актуальны, как и двести лет назад. Поэтому стратегам и лидерам двадцать первого века можно порекомендовать учитывать теории Клаузевица войны и стратегии потому, что они применимы и сегодня. В двух словах, Клаузевиц является теоретиком двадцать первого века.

Ключевые слова: Клаузевиц, политика, стратегия, разрешение конфликтов, безопасность. 
Мы считаем нашим вкладом в теорию не то, что мы думали, а как мы это придумали. Тиха фон Гайцзи, Болко фон Йотингер и Кристофер Бассфорд ${ }^{1}$

Карл фон Клаузевиц пространно изучается в течение 150 лет специалистами-теоретиками и признан одним из по настоящему великих писателей по вопросам войны. В последние годы многие положения его идей и концепций пользовались большим вниманием, продолжают оставаться актуальными и их часто используют в современных доктринах и в процессе обучения по гражданско-военным отношениям. Поэтому целью данной работы является анализ наиболее важных теоретических аспектов войны и стратегии, сформулированных Клаузевицем, некоторые из которых являются не подверженном влиянию времени вкладом в современное мышление и все еще актуальны для современных стратегов.

В поддержку этого утверждения будут использованы три критически важных пункта. Первый момент, это конвенциональная ссылка на его мышление: с одной стороны, «война есть продолжение политики»; с другой, «война есть акт проявления силы с целью заставить противника подчиниться нашей воле». ${ }^{2}$ Второй момент связан с его анализом природы войны и теории троицы. Последний момент касается его понимания природы стратегии.

Для начала можно поставить фундаментальный вопрос: в чем состоят наиболее важные вклады Клаузевица в теорию войны в смысле, что они актуальны для стратегов и сегодня? Другими словами, чему может научить прусский генерал девятнадцатого века представителя исполнительной власти или предпринимателя двадцать первого века о теории войны?

Клаузевиц применял научный, методологический подход к анализу войны во всех ее аспектах. В этой статье представлены и рассмотрены наиболее важные и не подверженные влиянию времени вклады Клаузевица в теорию войны и стратегии, и подчеркнуты их наиболее важные аспекты. Во-первых, особенно значим его известный вывод, что «Война есть просто продолжение политики другими средствами». ${ }^{3}$ Сущность этой теории содержалась в описание Клаузевица вертикального континуума войны (политики, стратегии и тактики), который он представил в стратегической парадигме «цели, способы и средства». Согласно ей, объясняет Клаузевиц, «... война сама по себе не отменяет политическое взаимодействие ... Войну нельзя отделить от политической жизни ....". ${ }^{4}$

1 Tiha von Ghyczy, Bolko von Oetinger, and Christopher Bassford, eds., Clausewitz on Strategy. Inspiration and Insight from a Master Strategist (New York: John Wiley, 2001), 185.

2 Carl von Clausewitz, On War (Princeton, New Jersey: Princeton University Press, 1989), 75.

3 Там же, 87.

4 Там же, 605. 
Приведенные выше выдержки раскрывают, как Клаузевиц ссылается на политическую цель войны. Это наблюдение очень точно схватывает ключевой аспект войны: ее подчиненность политике. Учение Клаузевица об отношениях между политикой и войной можно обобщить так: «Теория выполняет свою главную задачу, когда она используется для анализа составляющих элементов войны ... Тогда теория становится руководством для каждого, который хочет изучать войну по книгам». 5

Клаузевиц видит войну полностью подчиненной политике. В «О войне» он объясняет, что «Политическая цель - изначальный мотив войны - таким образом определяет, как военную цель, которую надо достигнуть, так и объем усилий, который для этого необходим». ${ }^{6}$ Согласно его видению, «таким образом, война является актом проявлением силы с целью заставить противника подчиниться нашей воле». ${ }^{7}$ Надо признать, что это определение остается актуальным и сегодня, с учетом того, что в современных конфликтах имеют место всевозможные виды асимметричных угроз (терроризм, организованная преступность, наркокартели и т.д.). Очевидно, в этом определении подчеркнута центральная роль боевых действий, что отличает войну от конфликта. В поддержку этой точки зрения Клаузевиц описывает войну как «... противостояние между основными интересами, которое разрешается кровопролитием - и единственно этим война отличается от других конфликтов.$^{8}$ Это дает четкое понимание отличия между войной и конфликтом, особенно в современной среде, в которой угрозы часто являются асимметричными. Однако, надо учитывать то, что отличает войну сегодня от войн, которые велись во времена Клаузевица. Ключевым отличием является некинетический аспект современной войны - а именно, информационная война. В результате глобализации и технологического развития, которое позволяет моментальную передачу сообщений с использованием различных информационных платформ, информационные кампании имеют жизненно важную роль для победы в современной войне путем покорения умов и сердец, а так же дискредитированием врага (например, в последнее время в Афганистане между НАТО и талибами).

В истории, в современном мире и в будущем, теории войны Клаузевица дают научные законы, с помощью которых человек может понять сущность войны. Для него, однако, война не была деятельностью, которая управляется научными законами, а скорее является столкновением воли и духовных сил противников. Соответственно, успешным был не тот командир, кто знает правила игры, а тот, который благодаря своему гению создает их. Именно теория и философия войны придает его работам не подверженную влиянию времени ценность.

\footnotetext{
Там же, 141.

Там же, 81.

Там же, 75.

8 Там же, 149.
} 
Клаузевиц еще важен сегодня и из-за его усилий понять внутреннюю сущность войны. Его подход, являющийся философским с методической точки зрения, нельзя интерпретировать как перечень или как количественную меру для рассмотрения войны. Когда речь идет об исключительно важном моменте, моральности войны, Клаузевиц заявляет: «моральный фактор является наиболее изменчивым из всех факторов и поэтому легко оказывает влияние на все другое». ${ }^{9}$ Нет никакой пользы от теории, которая не учитывает эти взаимосвязанные элементы - ненадежность всей информации, значение моральных факторов, и подчеркивая оба эти элемента, непредсказуемой реакции противника. Это одна из причин, по мнению Клаузевица, по которой моральные силы имеют настолько важное значение. В качестве другой существенной причины наиважнейшего значения моральных элементов войны Клаузевиц подчеркивает, что

Они составляют тот дух, который принизывает всю войну, и на начальном этапе они устанавливают тесную связь с волей, которая движет и руководит всей массой сил, практически сливаясь с ней, поскольку воля сама по себе является моральной величиной. ${ }^{10}$

Клаузевиц обсуждает моральные качества, требуемые от войск, заключая: «Неважно, насколько ясно мы отличаем гражданина и солдата в одном человеке ... дело войны всегда будет индивидуальным и отдельным. Следовательно, солдаты воспринимают себя в качестве членов некой гильдии». ${ }^{11}$

Кроме того, война есть некая «троица». Проще говоря, война - это население, вооруженные силы и государственное управление. ${ }^{12}$ Эти три аспекта являются как бы тремя разными кодексами законов. Среди этих сторон население является наиболее чувствительной стороной в смысле поддержки войны. Без общественной поддержки невозможно успешно вести войну. Чтобы располагать постоянной поддержкой населения, исключительно важно, чтобы общественность была хорошо информирована с тем, чтобы могла отличать «правильное» от «неправильного». Естественно, поддержка людей наиболее сильна в отношении правильного и неправильного - на практике, она становится безусловной - когда они напрямую подвергаются опасности. Опасностью может быть любая угроза, воспринимая ими, как прямая угроза безопасности их страны. Однако, надо подчеркнуть, что сегодня успех «троицы» так же зависит от международной поддержки по крайней мере в двух отношениях: легальность войны и международная поддержка вопросного государства. Важное значение международной поддержки можно наблюдать в случае вторжения США в Ирак в 2003 году, а также в случае Афганистана двумя годами раньше.

\footnotetext{
9 Там же, 97.

10 Там же, 184.

11 Там же, 187.

12 Там же, 89.
} 
На данном этапе стоит упомянуть рассуждения Бассфорда о модели «троицы» Клаузевица, в которых он указывает на следующее:

Троица Клаузевица всеохватна и универсальна, она охватывает субъективное и объективное; одностороннее и многостороннее; интеллектуальные, эмоциональные и физические компоненты явления войны в любом человеческом конструкте. Понимание ее в качестве центральной связывающей идеи теории Клаузевица поможет нам привести в порядок часто весьма запутанное столпотворение его идей и применять их полезным, сравнительным образом, как в отношении истории мира, в котором мы живем, так и в отношении его сегодняшних реалий. ${ }^{13}$

Никто не может выиграть войну, оставаясь пассивным; победы можно достичь, только действуя активно и решительно. Сочетание дипломатической, информационной, военной и экономической мощи (ДИВЭ) стало очень важным в современном мире. Для ведения контртеррористической борьбы исключительно важной является разведывательная деятельность. Она может сохранить много жизней, денег и времени и обеспечить инициативу против асимметрических угроз, появляющихся сегодня. Нет никакого искусственного заменителя троицы населения, вооруженных сил и государства. Вместо того, чтобы пытаться противопоставлять доказанную теорию и современные сложности конфликта и искать разногласия между ними, нужно глубже и аккуратнее исследовать потенциальные проявления человеческого поведения в постоянно меняющемся мире. Это будет способствовать более глубокому пониманию природы современного конфликта, в котором главным актором является человек. Наблюдается тенденция критиковать положение о троице в качестве синтеза трех центральных элементов, или «доминирующих тенденций», подчеркивая, что любая война состоит из насилия и ненависти. Что касается взаимодействия случайности, вероятности и элемента подчиненности, однако, модель троицы может помочь нам понять сущность динамики войны даже сегодня.

Лучшим путем к победе является так называемый западный способ ведения войны, поскольку он требует наибольшей инициативности и решительности и, следовательно, имеет большой шанс на успех. Как говорит Джеффри Паркер, этот подход к войне основан на пяти принципиальных положениях: «Превосходящая технология, дисциплина, агрессивная западная военная традиция, уникальная способность бросать вызовы и реагировать динамично и способность легко мобилизовать капитал». ${ }^{14}$ Все пять этих столбов имели место на протяжении всей истории и поэтому оказывают влияние на вооруженные силы Запада и сегодня. Это очевидно

13 Christopher Bassford, "The Primacy of Policy and the 'Trinity' in Clausewitz's Mature Thought," in Clausewitz in the Twenty-First Century, ed. Hew Strachan and Andreas Herberg-Rothe (New York: Oxford University Press, 2007), 74-90.

14 Geoffrey Parker, ed., The Cambridge History of Warfare (Cambridge: Cambridge University Press, 2005), 1. 
не только в отношении превосходящей технологии и военной дисциплины, но также и в отношении гибкости и адаптируемости западных военных структур и организаций перед лицом новых глобальных вызовов. Пятнадцать лет назад никто не мог представить себе военные формирования, которые будут успешны в сегодняшних условиях асимметричной войны. Хотя эти пять принципов считаются предпосылками для успеха, сегодняшняя война требует весьма тонкого равновесия между применением агрессивной военной стратегии и кинетических средств и использованием не-кинетически-ориентированных стратегий. Это особенно верно в отношение анти-повстанческих операций, подобных проводимым в Афганистане и Ираке.

Следующий важный момент касается значения стратегии. Слово «стратегия» часто используется в разном контексте. Этот термин происходит из

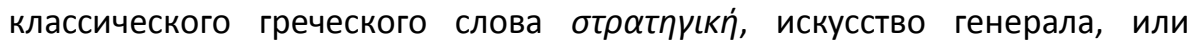
бтратпүóc. Согласно Клаузевицу, тактика учит нас, как использовать вооруженные силы в ходе боевых действий, тогда как стратегия использует боевые действия с целью выиграть войну. ${ }^{15}$ Поясняя это словами Клаузевица:

Стратегия есть использование боевых действий для достижения целей войны. Следовательно, стратег должен определить цель всей оперативной стороны войны, которая будет в согласии с ее конечной целью. Другими словами, он должен разработать план войны, и цель определит последовательность действий, направленных на ее достижение: на практике, сформировать конкретную кампанию и в ее рамках определить отдельные боевые действия. ${ }^{16}$

Иногда кажется, что значение военной стратегии размывается постоянно появляющимися связями с такими другими концепциями, как экономическая стратегия, стратегия развития, стратегия доминирования, стратегия превалирования, технологическая стратегия и т.д. Это приводит к заключению, что сегодня есть многочисленные сферы человеческого существования, которые требуют наличия собственных стратегий. Военная стратегия требует постоянного развития и инкорпорирования со стороны военных планировщиков; следовательно, военные стратеги должны быть знакомы с основными положениями других стратегий с тем, чтобы встречать вызовы безопасности и, в конечном итоге, выиграть войну. Это ни в коем случае не уменьшает историческое значение военной стратегии - на деле, как раз наоборот.

Ссылки на значение стратегии в понимании Клаузевица в наше время все еще подразумевает использование вооруженных действий, но другим областям уделяется гораздо больше внимания, чем в прошлом. Стратегия

15 Clausewitz, On War, 128.

16 Там же, 177. 
уже не просто перечисление целей, задач и заданий, но и то, как согласовать все эти элементы, чтобы добиться выполнения миссии.

Стратегия касается целей и средств для их достижения; она занимается самим высоким уровнем планирования, установлением четких конечных целей и созданием широкой картины возможностей для их реализации. Тогда как проигрыш на тактическом уровне войны не означает однозначно проигрыш войны, проигрыш на стратегическом уровне чаще всего означает, что война будет проиграна, если не будет изменена стратегия, заменено высшее военное руководство или и то, и другое: «Классическим средством стратегии является победа [в боевых действиях] - т.е. тактический успех; ее конечными целями, в окончательном анализе являются те цели, которые напрямую приводят к миру». ${ }^{17}$ Хотя мы живем в двадцать первом веке - в технологическом плане совершенно отличном от времени Клаузевица, - его фундаментальные определения все еще верны.

В заключение в этой работе утверждается, что стратегия Клаузевица дает концептуальную связь между конечными целями и средствами в мирное время и во время войны, а его теория войны все еще актуальна для современных стратегов. Сегодня имеют место развитие и изменения в технологии, географии, религии и политике - факторы, к которым его заключения надо адаптировать, с чем он, наверное, полностью бы согласился. Хотя его осознание диалектичности войны является слишком философским для некоторых из практиков, которым нужен перечень мероприятий для ведения операций, обзор работ Клаузевица важен для понимания главных вопросов и решений, даже когда история и реальность ограничивают применимость его абстракций к сегодняшнему опыту.

Война воспринимается как жестокая и безжалостная человеческая деятельность, являющаяся актом проявления силы для того, чтобы заставить противника подчиниться нашей воле, противоборство, разрешаемое кровопролитием. Война движется политикой и является ее органичной частью. Причиной войны являются интересы и потребность доминировать, как проявление основного инстинкта выживания. Для войны не нужны две стороны, которые хотели бы вести войну; если одна из сторон желает физического столкновения, оно случится; на деле, у инициирующей стороне есть преимущество, как у шахматиста, который играет белыми фигурами.

Так же, моральное состояние является психологической силой, которая ведет к победе, и на нее может оказывать положительное или отрицательное влияние идеология. Оно может принести чистую и славную победу или привести к военным преступлениям с моральным алиби. В отличие от морального духа, который помогает победить, туман и трение являются неизбежными и навязчивыми факторами в войне. То, что влияние этих факторов можно уменьшить путем обучения, дисциплины и высокой

17 Там же, 177. 
технологии, приводит к выводу, что у развитых стран больше шансов на победу, поскольку у них больше шансов на ослабление этих факторов.

Существенным элементом поддержки вооруженных сил во время войны является поддержка общественности, которая наиболее сильна, когда общество подвергается непосредственной опасности. Только активный и решительный комплексный подход может привести к победе. В плане эффективности наиболее успешным способом ведения войны является западный подход с его превосходящей технологией, дисциплиной и агрессивной военной традицией, наряду со способностью реагировать динамически и мобилизовать капитал. Что касается стратегии, она является одновременно искусством и наукой использования средств для достижения конечных целей политики. Определение стратегии является очень сложной деятельностью в современном исключительно сложном мире.

В итоге, если существует хорошая политика, из которой можно вывести стратегию и ее возможно будет применить с высоким уровнем эффективности наряду с аргументами, которые обеспечат непоколебимую поддержку населения и международного сообщества, то налицо будут благоприятные предпосылки для войны.

\section{6 авторе}

Доктор Ясмин Чаич - полковник и командир ЦПОПМ в Сараево. В число занимаемых им прежде должностей входят командирские и штабные должности, начиная от взводного уровня и до МО Боснии и Герцеговины. У него как военное, так и гражданское образование. Он закончил Национальный военный колледж НУО в Вашингтоне, США. У него степень магистра наук в сфере обороны и безопасности, полученная в Университете Сараево и магистра наук по стратегии национальной безопасности из НУО/США. Он защитил кандидатскую степень по обороне и безопасности в Университете Сараево и получил титул доцента в Американском университете в Боснии и Герцеговине. Он также является приглашенным лектором в Международном университете им. Барча в Сараево.

E-mail: jasmincajic@hotmail.com. 